\title{
Review of: "The Effect of Habitat Structural Complexity on Gastropods in Anarid Mangrove Wetland"
}

\author{
Everthon Xavier
}

Potential competing interests: The author(s) declared that no potential competing interests exist.

The study provides an analysis of diversity of gastropods in two microhabitats in the Persian Gulf, with the hypothesis that vegetated microhabitats would harbor higher richness of species than unvegetated microhabitats. This is an interesting experiment that could provide insights about the relations of gastropods and the environment. However, a few comments are important to be observed here:

1. In the discussion are cited many reason that explain the success ofPlatevindex tigrinus in pneumatophore zone, but nothing explains the success of Assiminea mesopotamica in same habitats. About mudflats, there is nothing in the article that explains why Pirenella cingulate and Littoraria intermedia were the dominant species in this areas. Need more discussion and explanation here.

2. Total organic carbon (TOC) and total organic nitrogen (TON) were identified as the environmental variables affecting the species composition of gastropods in Khuran mangrove, however it would be interesting to explore this fact further in the discussion (see other studies, as Pérez et al. 2018). What are the reasons that influence these environmental factors and why do these factors seem to influence gastropod communities so much?

3. There should be an explanation about the difference between the two studied habitats (e.g. Sheridan 1997; Halide et al. 2003; Chen et al. 2007), vegetated and unvegetated, because there is no mention in the discussion about the influences of these habitats on the community. Furthermore, the study could include a simple biomass analysis as in Wolff et al. (1993), for better understanding of the differences of these two habitats.

4. The study also found a low richness of species in comparison with other studies in similar regions: Malay peninsula, Thailand and Segara Anakan lagoon (Indonesia), as cited by the text. Despite that, there are no reasons for this low harboring? Besides the only mangrove tree species found at region, it is important to notice if exists other reasons (e.g. predators, low food availability, competition with other organisms) and whether they are also directly responsible for this low recruitment (see Bernardino et al. 2018). Although they have been cited in a generic way in the end of the text and perhaps cannot be measured by the analyzes presented here, these observations in situ are important for a better understanding of the relationships between gastropods and the environment.

These are just a few points that could have been included in the article and serve to expand this study in the future. Still, it remains an interesting read.

\section{References}


- Bernardino A.F., de Oliveira Gomes L.E., Hadlich H.L., Andrades R., Correa L. B. (2018). Mangrove clearing impacts on macrofaunal assemblages and benthic food webs in a tropical estuary. Marine Pollution Bulletin, 126, 228-235.

- Chen G.C., Ye Y., Lu C.Y. (2007). Changes of macro-benthic faunal community with stand age of rehabilitated Kandelia candel mangrove in Jiulongjiang Estuary, China. Ecological Engineering, 31(3), 215-224.

- Halide H., Ridd P.V., Peterson E.L., Foster D. (2003). Assessing sediment removal capacity of vegetated and nonvegetated settling ponds in prawn farms. Aquacultural engineering, 27(4), 295-314.

- Pérez A., Libardoni B.G., Sanders C.J. (2018). Factors influencing organic carbon accumulation in mangrove ecosystems. Biology letters, 14(10), 20180237.

- Sheridan P. (1997). Benthos of adjacent mangrove, seagrass and non-vegetated habitats in Rookery Bay, Florida, USA. Estuarine, Coastal and Shelf Science, 44(4), 455-469.

- Wolff W.J., Duiven A.G., Duiven P., Esselink P., Gueye A., Meijboom A., Moerland G., Zegers, J. (1993). Biomass of macrobenthic tidal flat fauna of the Banc d'Arguin, Mauritania. Hydrobiologia, 258(1), 151-163. 